\title{
Enhanced tribological properties of aligned graphene-epoxy composites
}

\author{
Yuefeng DU ${ }^{1}$, Zhenyu ZHANG ${ }^{1, *}$, Dong WANG ${ }^{2}$, Lezhen ZHANG $^{3}$, Junfeng CUI $^{1}$, Yapeng CHEN ${ }^{4}$, Mingliang $\mathbf{W U}^{1}$, \\ Ruiyang KANG ${ }^{1}$, Yunxiang LU ${ }^{4}$, Jinhong YU ${ }^{4}$, Nan JIANG ${ }^{4, *}$ \\ ${ }^{1}$ Key Laboratory for Precision and Non-Traditional Machining Technology of Ministry of Education, Dalian University of Technology, \\ Dalian 116024, China \\ ${ }^{2}$ Beijing Spacecrafts Manufacturing Factory Co., Ltd., China Academy of Space Technology, Beijing 100094, China \\ ${ }^{3}$ Weichai Power Co., Ltd., Weifang 261061, China \\ ${ }^{4}$ Key Laboratory of Marine Materials and Related Technologies, Zhejiang Key Laboratory of Marine Materials and Protective Technologies, \\ Ningbo Institute of Materials Technology and Engineering (NIMTE), Chinese Academy of Sciences, Ningbo 315201, China
}

Received: 11 October 2020 / Revised: 29 December 2020 / Accepted: 25 January 2021

(C) The author(s) 2021.

\begin{abstract}
The random distribution of graphene in epoxy matrix hinders the further applications of grapheneepoxy composites in the field of tribology. Hence, in order to fully utilize the anisotropic properties of graphene, highly aligned graphene-epoxy composites (AGEC) with horizontally oriented structure have been fabricated via an improved vacuum filtration freeze-drying method. The frictional tests results indicated that the wear rate of AGEC slowly increased from $5.19 \times 10^{-6} \mathrm{~mm}^{3} /(\mathrm{N} \cdot \mathrm{m})$ to $2.87 \times 10^{-5} \mathrm{~mm}^{3} /(\mathrm{N} \cdot \mathrm{m})$ with the increasing of the normal load from 2 to $10 \mathrm{~N}$, whereas the friction coefficient (COF) remained a constant of 0.109. Compared to the neat epoxy and random graphene-epoxy composites (RGEC), the COF of AGEC was reduced by $87.5 \%$ and $71.2 \%$, and the reduction of wear rate was $86.6 \%$ and $85.4 \%$ at most, respectively. Scanning electron microscope (SEM) observations illustrated that a compact graphene self-lubricant film was formed on the worn surface of AGEC, which enables AGEC to possess excellent tribological performance. Finally, in light of the excellent tribological properties of AGEC, this study highlights a pathway to expand the tribological applications of graphene-epoxy composites.
\end{abstract}

Keywords: graphene; aligned; epoxy composite; tribological performance

\section{Introduction}

Epoxy resin, as a high-performance thermosetting polymer, possesses various outstanding properties including superior tensile strength, high stiffness, and high chemical resistance. It has been widely applied in the fields of petrochemicals, aeronautics, automotive, and high-voltage electrical equipment [1-4]. However, the application of epoxy resin as a sliding element in tribology is limited, for its high brittleness and low fatigue-resistant performance resulting from its 3D cross-linking network construction [5-8]. Many researchers have dedicated to remedying this limitation and suggested that the tribological performance of epoxy resins can be significantly improved via blending epoxy resins with various nano materials like carbon nanotubes [6, 7], $\mathrm{Al}_{2} \mathrm{O}_{3}[10], \mathrm{TiO}_{2}[11,12], \mathrm{Si}_{3} \mathrm{~N}_{4}$ [13], and $\mathrm{SiO}_{2}$ [14].

Recently, graphene has been chosen as a unique nanofiller to improve the mechanical and tribological performance of epoxy resins, because of its extremely high strength, large specific surface areas, and easy shear capability [15-18]. Normally, however, graphene sheets are randomly dispersed in epoxy resins, which

* Corresponding authors: Zhenyu ZHANG, E-mail: zzy@dlut.edu.cn; Nan JIANG, E-mail: jiangnan@nimte.ac.cn 
restricts the full utilization of the anisotropic properties of graphene enabled by its laminated structure. To further enhance the tribological performance of graphene-epoxy composites, graphene is generally assembled into an oriented structure in composites by several methods like layer-by-layer self-assemble method [19, 20], magnetic field-induced [21, 22], liquid crystal [23, 24], and vacuum filtration method [25, 26]. However, those methods are mainly deployed to improve the thermal and electric conductivity of polymers. Few of them focus on enhancing the tribological performance of the polymer. For instance, Liu et al. prepared aligned graphene-bismaleimide composites via magnetic field-induced methods $[21,22]$. The friction coefficient (COF) of as-prepared composites with $0.6 \mathrm{wt} \%$ graphene content is 0.07 , which is much lower than pure bismaleimide. Besides, factors limited the application of those methods might belong to difficult preparation of 3D aligned monoliths for layer-by-layer method, high processing cost of magnetic field-induced method, and the narrow range of graphene concentration of liquid crystal method.

Being in such a dilemma, the method of vacuum filtration is proposed as a convenient and feasible strategy to fabricate aligned graphene monoliths because of its relative lower demands for experimental facilities, operative difficulty, pollution treatment, and processing cost. However, scarce studies investigate the tribological performance of aligned graphene-epoxy composites (AGEC) prepared by vacuum filtration method. Normally, liquid will be completely drained after vacuum filtration processing [26-28], resulting that graphene layers pack tightly. Consequently, the penetration of epoxy is obstructed and the composite cannot bear a high normal load.

To overcome these restrictions, this paper attempts to prepare AGEC by adding freeze-drying into the vacuum filtration method. In this way, the as-prepared AGEC is equipped with a lamellar structure for the effective penetration of epoxy into the gap between graphene layers, which is different from the random graphene-epoxy composites (RGEC) prepared by a solution blending method. Then, tribological performances of AGEC, RGEC, and neat epoxy were respectively carried out on a tribo-tester under normal load ranging from 2 to $10 \mathrm{~N}$. The results indicated that AGEC possesses the best tribological properties among three materials. Furthermore, in order to uncover the wear mechanisms, an extensive analysis of the worn surfaces was investigated via scanning electron microscope (SEM), optical microscope, and Raman spectrometer. The enhanced tribological properties of AGEC are attributed to the formation of a stable and compact graphene film on the worn surface, which can act as a lubricant and protecting film.

\section{Experiment}

\subsection{Materials}

Graphene sheets were purchased form the Ningbo Morsh Technology Co., Ltd. (China). Epoxy resin (6105) was obtained from DOW Chemicals (USA), and methyl-hexahydrophthalic anhydride (MHHPA) used as a curing agent was provided by Zhejiang Alpharm Chemical Technology Co., Ltd. (China). Neodymium(III) 2,4-pentanedionate supplied by Aldrich Chemicals was used as a curing accelerator. Silicon nitride balls of $6 \mathrm{~mm}$ diameter and ethanol were respectively purchased from the Shaoxing Shangyu Yixin ball industry Co., Ltd. (China) and Sinopharm Chemical Reagent Co., Ltd. All reagents were of analytical grade and used as received without further purification.

\subsection{Preparation of RGEC}

First, epoxy resin and Neodymium(III) 2,4-pentanedionate were stirred at $80{ }^{\circ} \mathrm{C}$ for $8 \mathrm{~h}$ with the mass ratio of 1,000:1. After cooling to the room temperature, the hybrid was further mixed with the curing agent (MHHPA) with the mass ration of 100:95 to produce the homogeneous solution. Then, this solution was mixed with the graphene sheets. The content of graphene was $5.3 \%$, which is same as the graphene content of AGEC. Next, the resulting graphene-epoxy mixture was put into a vacuum chamber and degassed at $55^{\circ} \mathrm{C}$ for $3 \mathrm{~h}$. Finally, the graphene-epoxy mixture was pre-cured at $135^{\circ} \mathrm{C}$ for $2 \mathrm{~h}$ and then completely cured at $165^{\circ} \mathrm{C}$ for $14 \mathrm{~h}$.

\subsection{Preparation of AGEC}

Figures 1(a)-1(c) illustrate the schematic diagram of the fabrication processes of AGEC, following three 


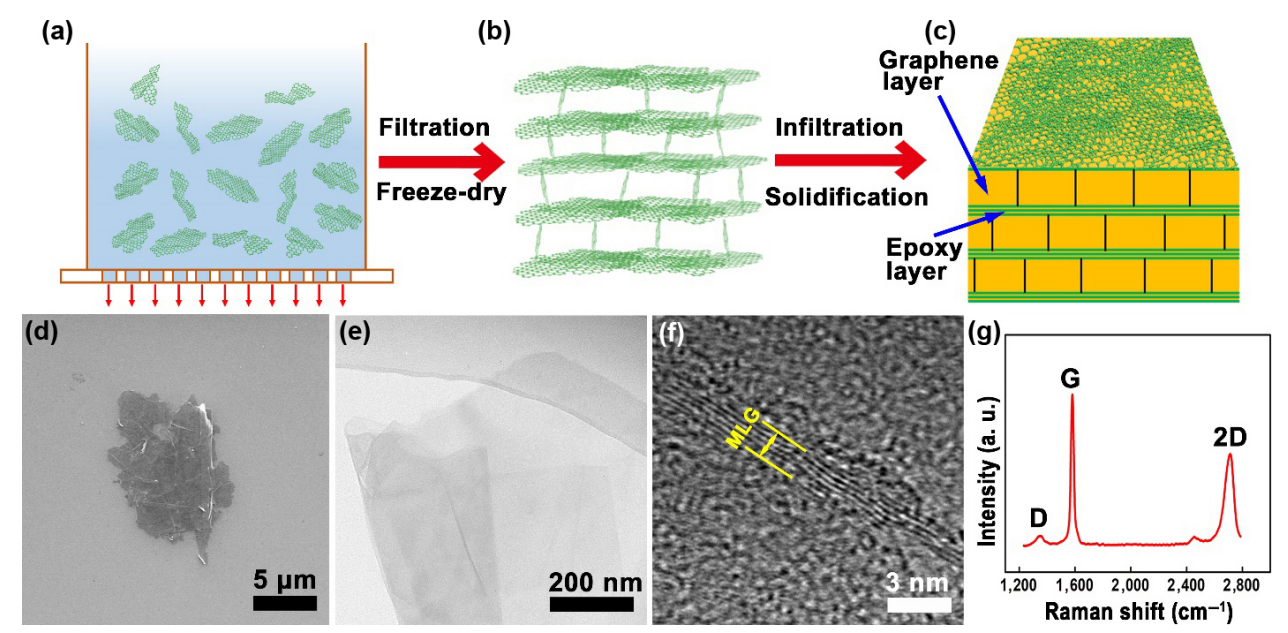

Fig. 1 (a-c) Schematic diagram of the fabrication processes of AGEC; (d) SEM image, (e) transmission electron microscopy (TEM) image, (f) high-resolution TEM image, and (g) Raman spectrum of the graphene sheets.

steps: vacuum filtration, freeze-drying, and solidification. Firstly, graphene sheets were first added into a mixture of water and ethanol (at a volume ratio of 6:1), then they were ultrasonicated and stirred for $2 \mathrm{~h}$. Next, the obtained hybrid was vacuum-filtrated with a nylon membrane (pore size: $15 \mathrm{um}$ ) to get the aligned wet graphene monolith with the thickness of $15 \mathrm{~mm}$, as shown in Fig. 1(a). After that, the monolith was immediately put into a freezer $\left(-18{ }^{\circ} \mathrm{C}\right)$ for $24 \mathrm{~h}$ to completely frozen. Subsequently, the fully frozen samples were freeze-dried at low temperature $\left(-60^{\circ} \mathrm{C}\right)$ and low pressure (20 Pa) for $36 \mathrm{~h}$ to obtain the aligned porous graphene framework, as shown in Fig. 1(b). Afterward, the framework was immersed into the homogeneous solution as shown in Section 2.2, and then was degassed under vacuum condition at $55^{\circ} \mathrm{C}$ for $6 \mathrm{~h}$, in order to make epoxy homogeneous solution penetrate the porous framework completely. Finally, the curing condition was in accordance with Section 2.2.

\subsection{Characterizations}

The lateral size of the graphene sheets was characterized by SEM (Quanta FEG250, FEI, USA). Raman spectra were recorded via a Reflex Raman System (Renishaw PLC, Wotton-under-Edge, UK). The TEM (FEI Tecnai F20, USA) images and thickness of graphene sheets were observed. The surface and cross-sectional morphology of aligned graphene framework and aligned graphene-epoxy composites were characterized by SEM. Thermogravimetric analysis (TGA) was taken via a PYRIS Diamond ${ }^{\mathrm{TM}}$ system (PerkinElmer, USA) in nitrogen atmosphere at a heating rate of $20^{\circ} \mathrm{C} \cdot \mathrm{min}^{-1}$.

\subsection{Tribological tests}

Tribology tests were performed by a ball-on-disk reciprocating tribo-tester (UMT-3, CETR) at room temperature under atmospheric condition. Before testing, the composite was firstly cut into flakes with the size of about $10 \mathrm{~mm} \times 15 \mathrm{~mm} \times 2 \mathrm{~mm}$ using low-speed sawing, and the cutting direction was parallel to graphene orientation. After that, the obtained flake was polished by 3,000 grit papers. The mean roughness of neat epoxy, RGEC, and AGEC specimens measured by confocal microscopy (Leica DM2500 M, Germany) is $1.24,1.09$, and 1.35 , respectively. The counterpart balls were commercially available silicon nitride with a diameter of $6 \mathrm{~mm}$. All the samples and balls were cleaned with acetone by ultrasonication and dried by hot air before each test. During the tribological test, the normal load $L$ ranged from 2 to $10 \mathrm{~N}$. The sliding frequency $f$ and sliding length $h$ were $2 \mathrm{~Hz}$ and $5 \mathrm{~mm}$, respectively. The duration of each test was $1 \mathrm{~h}$. The friction coefficient was obtained by the computer automatically. After each friction tests, the wear cracks were observed by confocal microscopy (Leica DM2500 M, Germany) and SEM. The cross-sectional area $A_{\mathrm{c}}$ of wear cracks was characterized by surface profile measuring instrument. The wear rate $(\tau)$ was calculated by the following equations:

$$
\begin{aligned}
& \tau=V \cdot L^{-1} \cdot S^{-1} \\
& V=A_{\mathrm{c}} \cdot S
\end{aligned}
$$




$$
S=2 \times h \times f \times T
$$

where $V, S$, and $T$ are the wear volume, sliding distance, and sliding time, respectively. All tests were repeated for three times in the same condition, and the average values were adopted in our results.

\section{Results and discussion}

\subsection{Characterization}

As displayed in Fig. 1(b), after freeze-drying, aligned porous graphene framework was obtained. This structure is favorable to infiltrate epoxy into the gap between graphene layers. After the infiltration and solidification of epoxy, AGEC with lamellar structure was fabricated finally, as shown in Fig. 1(c). Typical SEM and TEM images of the graphene sheet are shown in Figs. 1(d) and 1(e). SEM image shows the stacked multi-layer graphene sheet, and the lateral size of the graphene sheet was about $10 \mu \mathrm{m}$. Hou et al. [29] have shown that large graphene sheets $(13 \mu \mathrm{m})$ can form better-aligned arrangement monolith than the small ones $(4 \mu \mathrm{m})$. As demonstrated by TEM images, the graphene sheet was transparent and corrugated. Figure 1(f) shows a typical high-resolution TEM image of the graphene sheets edge structure, indicating that each graphene sheet was composed of 5-6 individual graphene layers and the thickness was about $3 \mathrm{~nm}$. Figure 1(g) displays the Raman spectrum of graphene sheets with three characteristic peaks. The peaks located at $1,350,1,580$, and $2,700 \mathrm{~cm}^{-1}$ can be assigned to $D, G$, and 2D peaks of graphene, respectively. The weak intensity of $\mathrm{D}$ peak indicated the less defect degree of graphene sheets. Moreover, the $I_{2 \mathrm{D}} / I_{\mathrm{G}}$ ratio in the spectrum suggested that the layer number of the graphene nanosheet was above 5 layers.

Figures 2(a) and 2(c) shows the cross-sectional and top-view microscopic morphologies of porous aligned graphene monolith. The porous aligned graphene monolith was successfully obtained via vacuum filtration freeze-dry method. The graphene sheets assembled layer-by-layer under the action of directional flowing of solvents [30]. Between the graphene layers, there were many gaps and micropores, resulting from the sublimation of ice crystals. More details, shown in the higher magnification SEM image in Fig. 2(b), indicated the horizontal arrangement of graphene sheets and the porous structure. Figure 2(d) shows the cross-sectional SEM image of porous graphene monolith, which was obtained by freeze-drying the graphene solution with the same graphene content as AGEC. Comparing to Figs. 2(a) and 2(c), the graphene orientation of porous graphene monolith was completely random. Figures 2(e) and 2(f) show the height of the porous
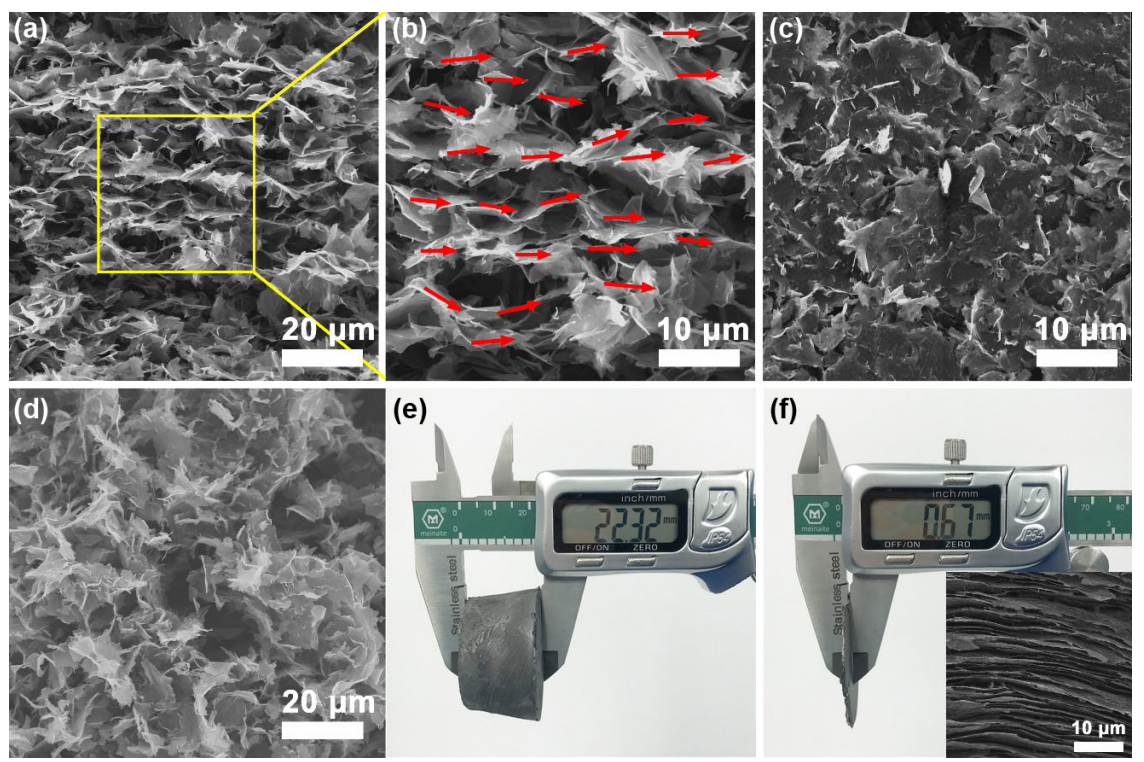

Fig. 2 (a, b) Cross-sectional and (c) top-view SEM images of the porous aligned graphene monolith; (d) cross-sectional SEM image of random porous graphene monolith; (e) height of the porous aligned graphene monolith after freeze-dry; and (f) aligned graphene paper after draining the liquid. 
aligned graphene monolith after freeze-dry $(22.32 \mathrm{~mm})$ and aligned graphene paper $(0.67 \mathrm{~mm})$ after draining the liquid, respectively. It is obvious that there was a huge difference in height between them under the same weight, with many identifiable gaps and pore inside the former. The inset in Fig. 2(f) illustrates the tightly stacked graphene layers, which is not conducive to the penetration of epoxy. With the infiltration of epoxy into the monolith and solidification, AGEC was obtained. Cross-sectional SEM images in Figs. 3(a) and $3(\mathrm{~b})$ revel the oriented layer structure of AGEC, which was similar to the "brick-and-mortar" arrangement. Top-view SEM image shows the laminated structure of AGEC, as shown in Fig. 3(c), indicating its anisotropic property. Unlike the huge difference between cross-sectional and top-view morphologies of AGEC, there were not obvious distinctions between them, as the cross-sectional and top-view morphologies of RGEC shown in Figs. 3(d) and 3(e). Typical TGA curve of AGEC is given in Fig. 3(f), demonstrating a residual weight of $\sim 5.3 \mathrm{wt} \%$ at $1,000{ }^{\circ} \mathrm{C}$.

\subsection{Tribological properties of AGEC}

Figure 4 shows the tribological properties of AGEC, RGEC, and neat epoxy. The graphene content of RGEC was the same as AGEC. The results of the average $\mathrm{COF}$ and wear rate as a function of normal load are illustrated in Figs. 4(b) and 4(c) at a sliding speed of $2 \mathrm{~cm} \cdot \mathrm{s}^{-1}$ for $60 \mathrm{~min}$ under ambient conditions. The $\mathrm{COF}$ and wear rate of neat epoxy were quite high, owing to the poor tribological properties induced by its 3D cross-linking network structure [9]. However, the COF and wear rate of RGEC were reduced significantly after blending with graphene. This result is consistent with previous research which demonstrated that graphene can significantly improve the mechanical and tribological performance of epoxy resin [15, 31, 32]. Finally, AGEC had the lowest COF and wear rate among them. This outstanding tribological performance of AGEC may be attributed to the fact that the horizontally aligned arrangement can take full advantage of the anisotropic properties of graphene. In Fig. 4(b), the COF of neat epoxy and RGEC almost linearly decreased with the increasing normal load from 0.878 to 0.661 and from 0.411 to 0.264 , respectively. This trend confines with the results of previous research [33-35], in which the friction force of epoxy is a sublinear function of normal load, rather than follows the Amontons' law, due to the existence of adhesion forces between two counterfaces. On the contrary, the mean COF of AGEC under each normal load was roughly the same, as the lowest COF was 0.109 under the load of $10 \mathrm{~N}$, and the highest COF was 0.118 under the load of $2 \mathrm{~N}$, indicating that the friction force of AGEC was proportional to the normal load, following the Amontons' law. Meanwhile,
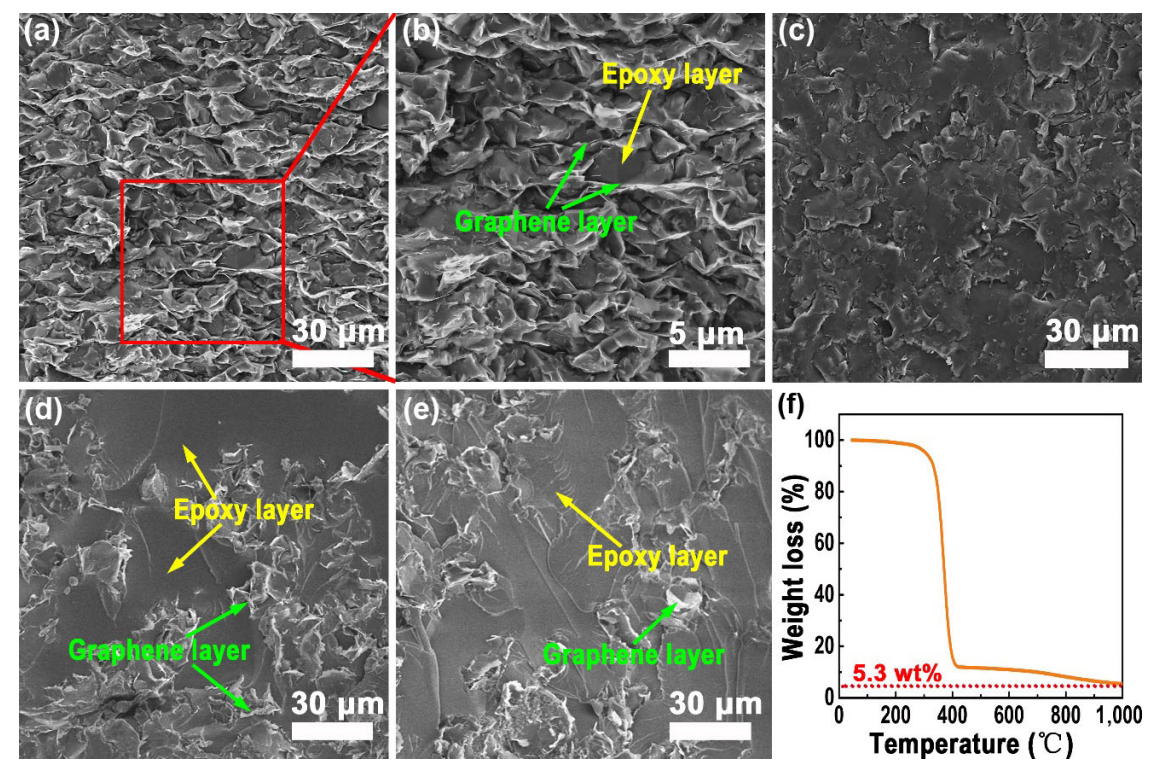

Fig. 3 (a, b) Cross-sectional SEM images of AGEC; (c) top-view SEM image of AGEC; (d) cross-sectional SEM image of RGEC; (e) top-view SEM image of RGEC; and (f) TGA curve of AGEC. 
the COF of AGEC as a function of sliding cycles for various normal load from 2 to $10 \mathrm{~N}$ is illustrated in Fig. 4(a). Each curve is smooth and the COF barely changes with time. The reason why AGEC and RGEC show different tendencies of COF is that the graphene layers near the surface can form self-lubricating film, which avoid direct contact and dramatically reduce the adhesion forces between two counterfaces. As shown in Fig. 4(c), the wear rate of AGEC and neat epoxy increased with increasing load from $5.19 \times 10^{-6}$ to $2.87 \times 10^{-5} \mathrm{~mm}^{3} /(\mathrm{N} \cdot \mathrm{m})$ and from $4.42 \times 10^{-5}$ to $7.60 \times 10^{-5}$ $\mathrm{mm}^{3} /(\mathrm{N} \cdot \mathrm{m})$, respectively. In contrast, the wear rate of RGEC decreased with increasing load from 2 to $6 \mathrm{~N}$, and was exceeded by that of AGEC when the normal load reached $8 \mathrm{~N}$.

In order to further reveal the wear behavior, the wear tracks were investigated using optical microscope and SEM. Figure 5 shows the optical microscopy images and cross-sectional profiles of the wear tracks of RGEC specimens after $1 \mathrm{~h}$ testing. In Figs. 5(a)-5(e), it is clear that, for all loads condition $(2-10 \mathrm{~N})$, the wear surface exhibited many large-size compacted debris with relatively smooth surface caused by plastic shearing, indicating the existence of adhesive wear on the worn surface [10, 33, 36]. More details about compacted debris are shown in the SEM images of Fig. 6. In Fig. 6(a), one of the compacted debris attached to the worn surface. High magnification SEM image in Fig. 6(b) clearly shows the edge of debris. In addition, the size and number of compacted debris increased with the increasing incremental normal load. Moreover, some scratches also existed on the worn surface and displayed a sign of abrasive wear, which became severer with the increasing load. Figure 5(f) illustrate the cross-section profiles of each wear track under different normal load. The depth and width of wear
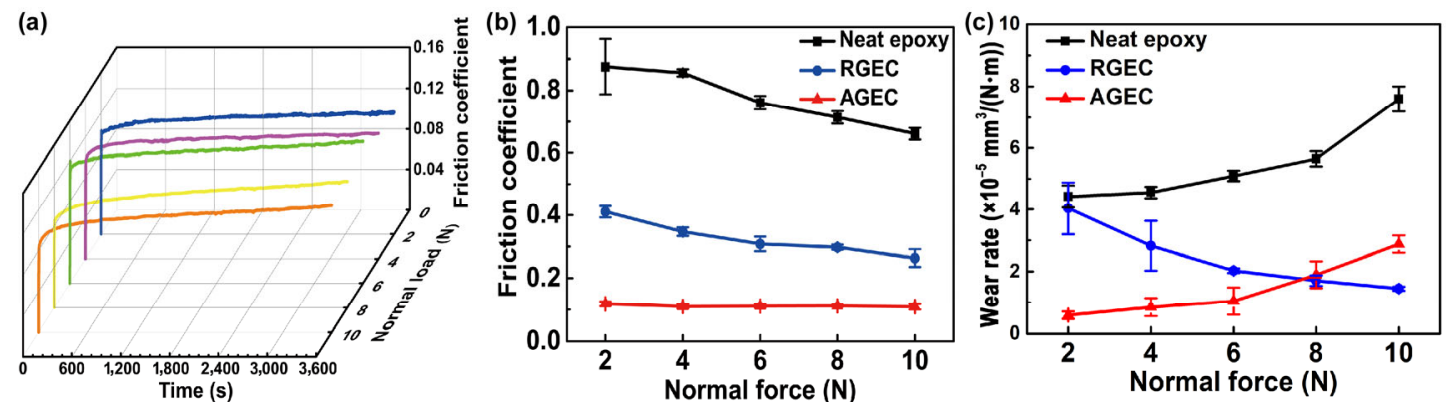

Fig. 4 (a) COF of AGEC as a function of sliding cycles for various normal load from 2 to $10 \mathrm{~N}$; (b, c) COF and wear rate as a function of normal load.
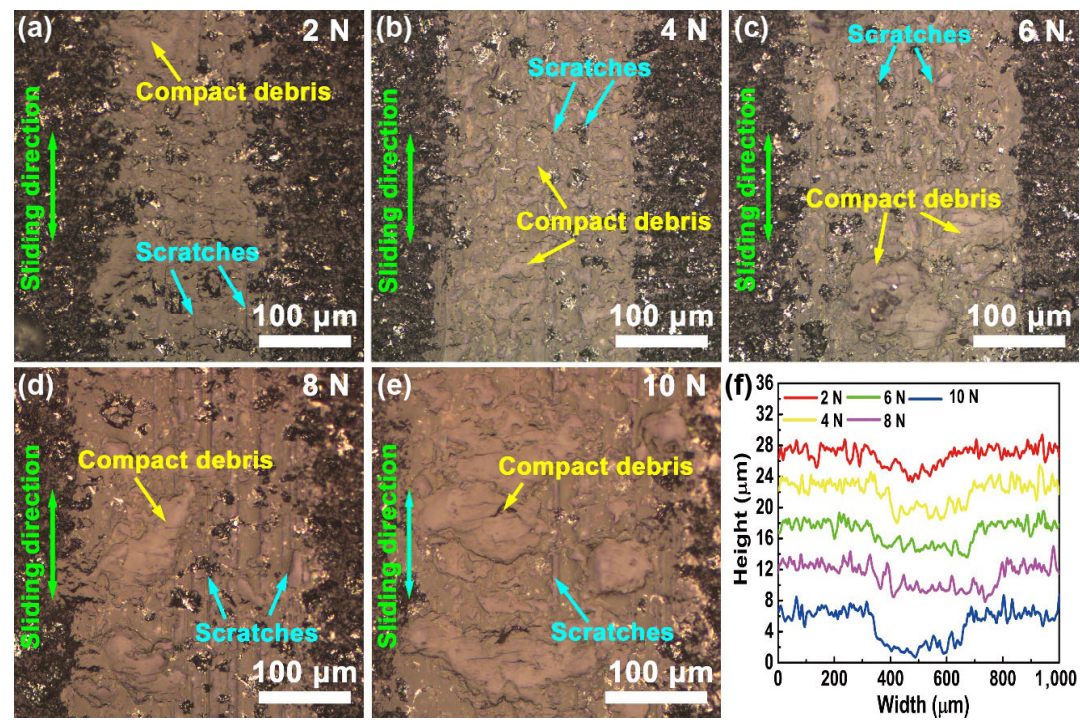

Fig. 5 (a-e) Optical images of wear tracks formed on RGEC specimens under 2-10 N normal load after $1 \mathrm{~h}$ testing and (f) cross-section profiles of each wear track. 

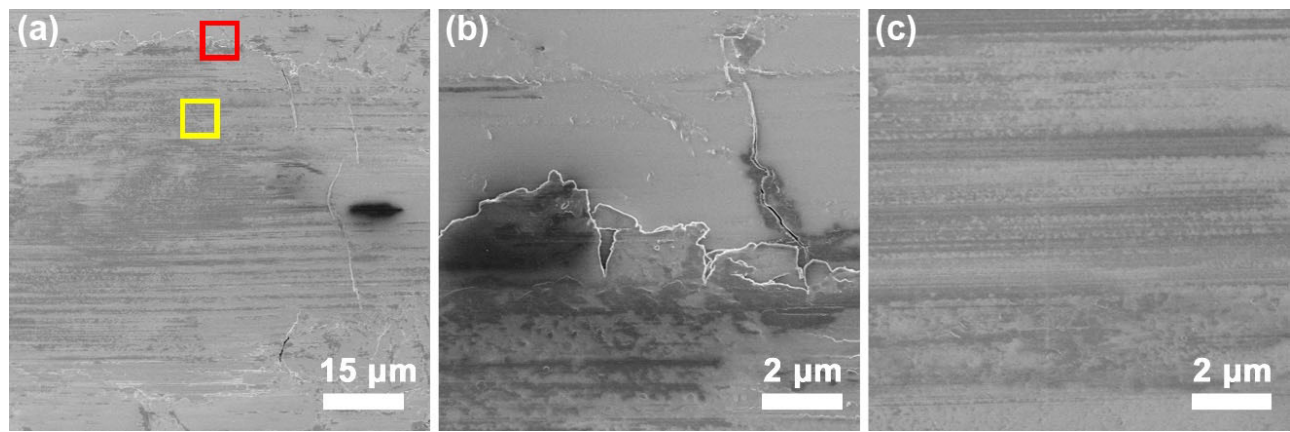

Fig. 6 (a) SEM image of compacted debris; (b) high magnification SEM image of edge in red box of (a); and (c) high magnification SEM image of scratches in yellow box of (a).

tracks gradually became deeper and broader with the increasing normal load. According to Eq. (2), the wear volumes of RGEC increased with increasing normal load. However, based on the observation of wear surface, as shown in Fig. 6(a), there were many scratches on the surface of compacted debris, and high magnification SEM image about scratches in yellow box is shown in Fig. 6(c). It can be concluded that large-size compacted debris attached on the sliding surface can protect the material underneath and reduce abrasive wear to some degree. This may be the reason why the wear rate of RGEC decreased with increasing load. Namely, the growth rate of wear volumes was not as fast as the normal load. Figure 7 illustrates the SEM morphologies of wear tracks on the neat epoxy and RGEC samples under different loads (4 and $8 \mathrm{~N}$ ). The fatigue cracks existed on all tracks, demonstrating that fatigue wear was the dominant wear behavior of both materials under sliding. For the neat epoxy, only high density of small fatigue cracks was observed on the tracks formed under normal load of $4 \mathrm{~N}$, as shown in Fig. 7(a). However, in Fig. 7(b), when normal load increased to $8 \mathrm{~N}$, the fatigue cracks were much longer than the counterpart under the normal load of $4 \mathrm{~N}$. Additionally, a large area of composite on the left of Fig. 7(b) delaminated from the buck materials, which was resulted from the extension of fatigue cracks. Regrading to the RGEC samples, low density of fatigue cracks and scratches were observed on the tracks formed both under the normal loads of 4 and $8 \mathrm{~N}$, as displayed in Figs. 7(c) and $7(\mathrm{~d})$. Though there were still peeling pits on the track in Fig. 7(d), the delamination was much weaker than that in Fig. 7(b), demonstrating that the addition of graphene in RGEC sample could effectively reduce
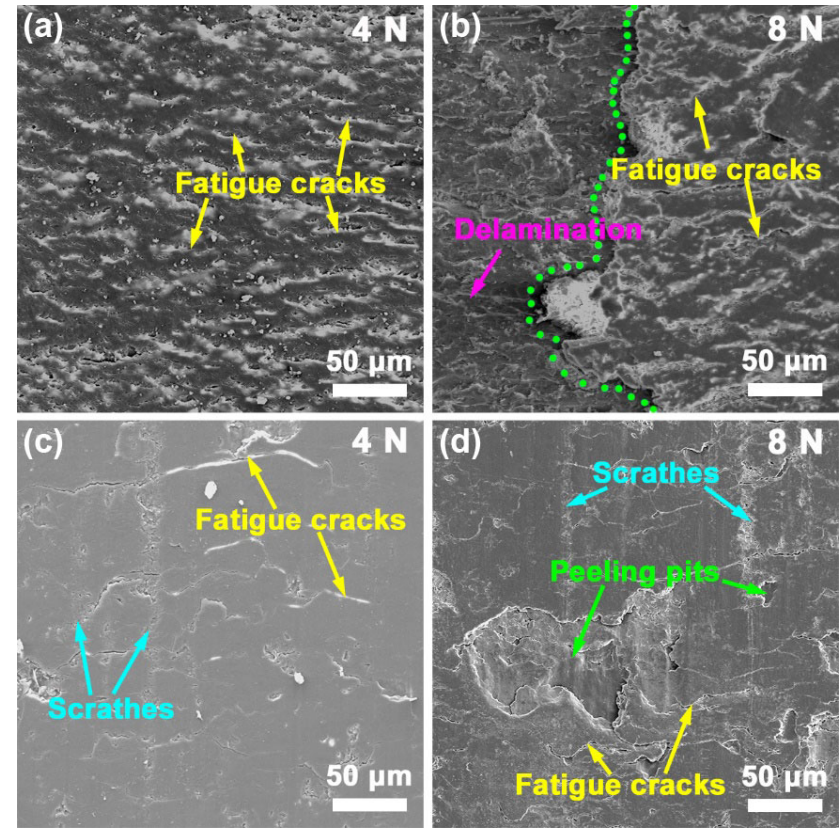

Fig. 7 (a) and (b) SEM images of wear tracks formed on neat epoxy specimens under the normal load of 4 and $8 \mathrm{~N}$; (c) and (d) SEM images of wear tracks formed on RGEC specimens under the normal load of 4 and $8 \mathrm{~N}$.

wear under sliding.

As shown in Figs. 8(a)-8(e), the optical microscopy images of the wear tracks of AGEC, the most distinctive feature was that a compacted film attaching on the sliding surface. The compact film was formed under shear of tangential force. Moreover, its area increased with the increasing normal load and almost covered the sliding surface when the normal load exceeds $4 \mathrm{~N}$. It should be mentioned that the scratches only be detected on the compact film in Figs. 8(c)-8(e), indicating that the compact film can act as a protective film and thus reduce the wear of AGEC. This is different from RGEC, in which a lot of scratches can be observed on 

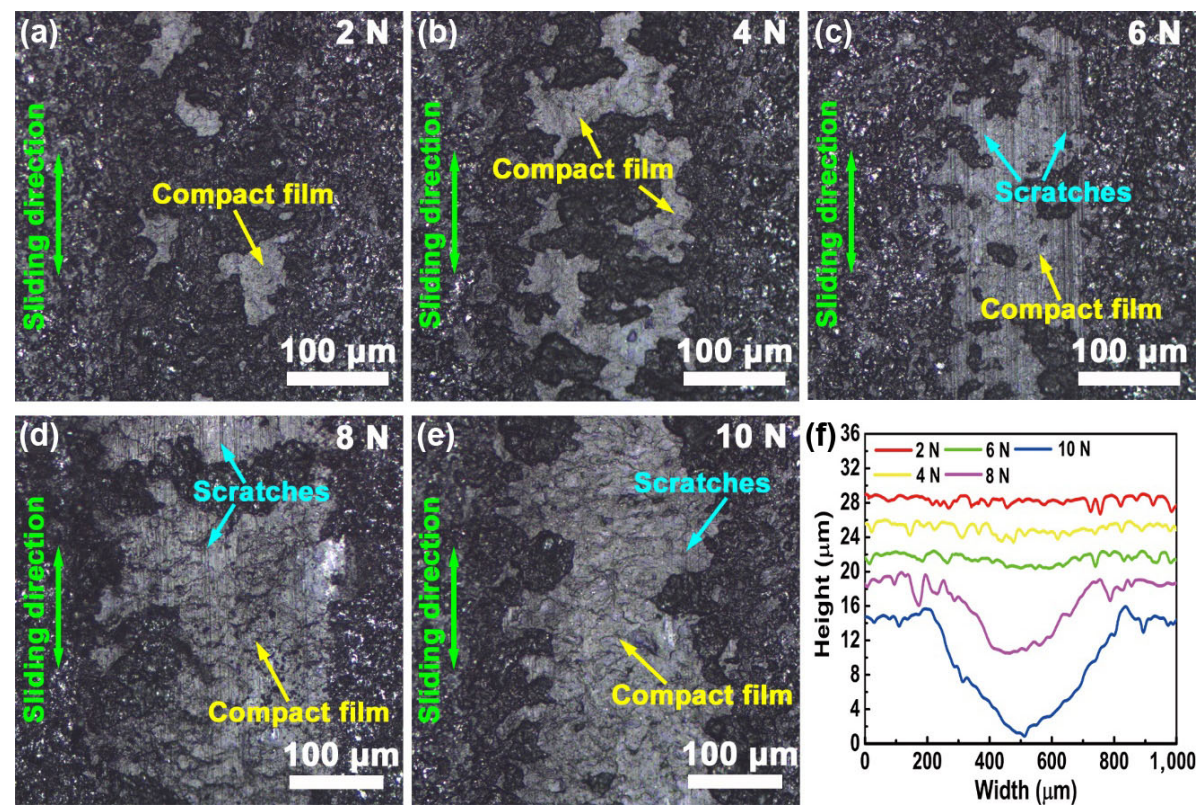

Fig. 8 (a-e) Optical images of wear tracks formed on AGEC specimens under 2-10 N normal load after 1 h testing; (f) cross-section profiles of each wear track.

the worn surface. Therefore, it is reasonable to believe that AGEC has better anti-wear performance compared to RGEC. Figure 8(f) shows the cross-section profiles of each wear track on AGEC specimens under different normal loads. The depth of wear tracks on AGEC specimen did not change significantly and became smaller than the counterpart of RGEC when the normal load was less than $8 \mathrm{~N}$. Nevertheless, the width of wear tracks suddenly became deeper when the load was up to $8 \mathrm{~N}$. So did the width of wear tracks. This was consistent with the trend of wear rate in Fig. 4(c).

Details of compact film surface on AGEC specimen are displayed in Fig. 9. As shown in Fig. 9(a), compact film surface under $4 \mathrm{~N}$ normal load is quite flat and smooth, while fatigue cracks, peeling pits, and scratches can be barely observed on it. Moreover, plate-like debris was exhibited on the wear surface. In Fig. 9(b), high-resolution SEM image displays more information about compact film surface and indicates that compact film was formed by compacting numerous plate-like debris under the action of normal load during the sliding process. When the normal load exceeded $8 \mathrm{~N}$, the compacted film surface is not smooth anymore and existed many cracks and debris, as shown in Fig. 9(c), resulting the peeling of compacted film and increased wear rate. Furthermore, Raman spectroscopy was employed to examine the properties wear condition of this compact film. Figure 9(c) displays the Raman spectra varied with normal load. The presence of D peak, G peak, and 2D peak indicated that the compacted films contain graphene sheet. However, compared to the Raman spectra in Fig. 1(d), the difference was that the intensity of $\mathrm{D}$ peak was higher

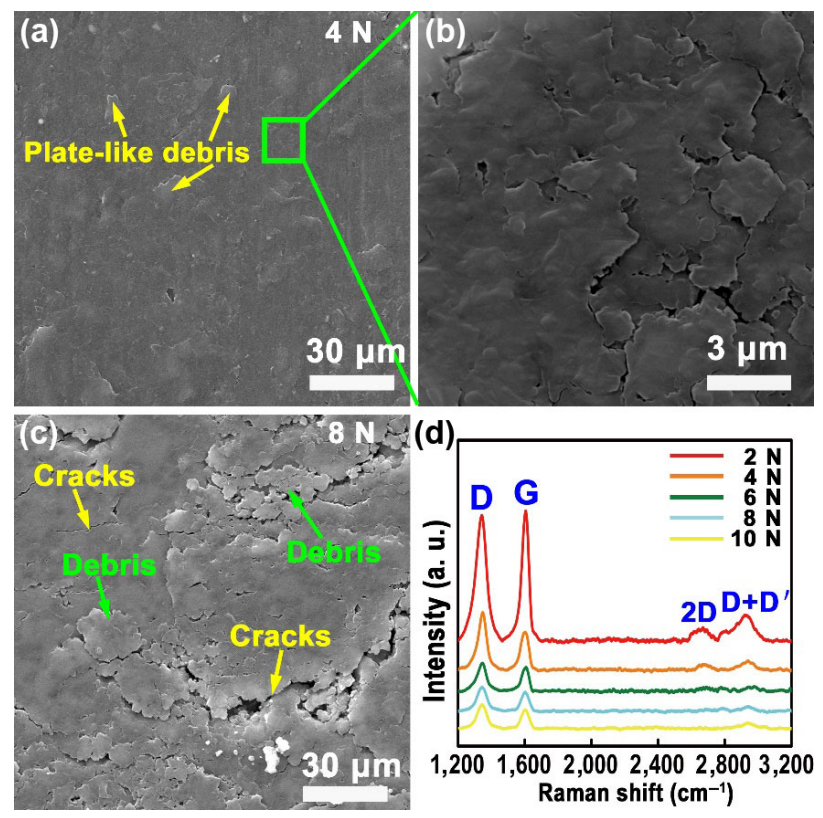

Fig. 9 (a, b) SEM images of compact film on AGEC specimen under $4 \mathrm{~N}$ normal load; (c) SEM image of compact film on AGEC specimen under $8 \mathrm{~N}$ normal load; and (d) Raman spectra of compact films surface varied with normal load. 
than $G$ peak, while the intensity of $2 \mathrm{D}$ peak became very weak. Besides, there existed another characteristic peak located at 3,080 $\mathrm{cm}^{-1}$, namely D+D'. These changes suggested that graphene sheets in compacted film became defected and disordered during the sliding process $[37,38]$. Furthermore, the intensity of Raman peak was decreased with the increased normal load, indicating that the wear condition of compacted films became sever under high normal load.

The tribological mechanism of AGEC is schematically illustrated in Fig. 10. In the beginning, despite the compacted films haven't been formed, some graphene sheets have already covered the sample surface. Hence, the COF in the running-in period is not high. Meanwhile, the higher individual asperities (blue region) on the contact area are removed, as shown in Fig. 10(a). The subsurface graphene layer is exposed, and further the scattered graphene sheets form the compact self-lubricating film under normal load during the sliding process. Once the compact selflubricating film is formed, directly sliding interaction between AGEC and $\mathrm{Si}_{4} \mathrm{~N}_{3}$ counterparts changes to relative sliding between graphene sheet [39], as shown in Figs. 10(b) and 10(c). According to the Bowden and Tabor concept $[39,40]$, hard materials with soft lubricant films possess a low COF. In this model, the friction force is determined by the shear strength of softer compact graphene self-lubricant film, while the hard epoxy substrate bears the load. It is reported that the COF of graphene film is about 0.1 at macroscopic in air $[41,42]$, which confines with the results in this paper. Furthermore, the hardness of AGEC (21.84 \pm $2.47 \mathrm{HV})$ was similar to that of RGEC $(22.46 \pm 1.11 \mathrm{HV})$. As the test proceeds, this film will be worn out, and thus the red region in Fig. 10(a) (residual epoxy layer) will be peeled out gradually. In the subsequent sliding, graphene layers below the epoxy layer will be exposed to form new compact self-lubricant film again. It is worth mentioned that AGEC is not aligned strictly in whole sample region or long range. There are mismatches between each part or short rang, indicating that, in the same plane, the sample is mixed with epoxy layer and graphene layer. It means that, no matter how the surface is worn, graphene sheets will be exposed continually to the worn surface, resulting the stationary COF curve without fluctuations. For these reasons, AGEC has a lower COF compared with RGEC. This film also plays a crucial role as a protecting film [43], reducing the wear of composite bulk, benefiting from the excellent anti-wear properties of graphene sheets. Besides, this film can reduce the contact stress by smoothing the contact surface, while the contact stress is the determining factor affecting the rate of crack propagation and the contact temperature $[9,11,44]$. Hence the wear rate of AGEC is also lower than RGEC. However, as the normal load increased to $8 \mathrm{~N}$, a lot of defects such as cracks and delamination appear on the worn surface, causing serious wear of compacted film. Since the wear rate of the solid lubricant system is determined by the wear rate of the lubricant films, the wear rate of AGEC increased rapidly under the high normal load.

\section{Conclusions}

In summary, the current study developed an improved vacuum filtration freeze-drying method to prepare AGEC, which comprises of three steps: (a) vacuum filtration; (b) freeze-dry; and (c) solidification. Scanning electron microscope (SEM) observations reveal the horizontally oriented arrangement and the layer structure, consisting of aligned graphene layer and
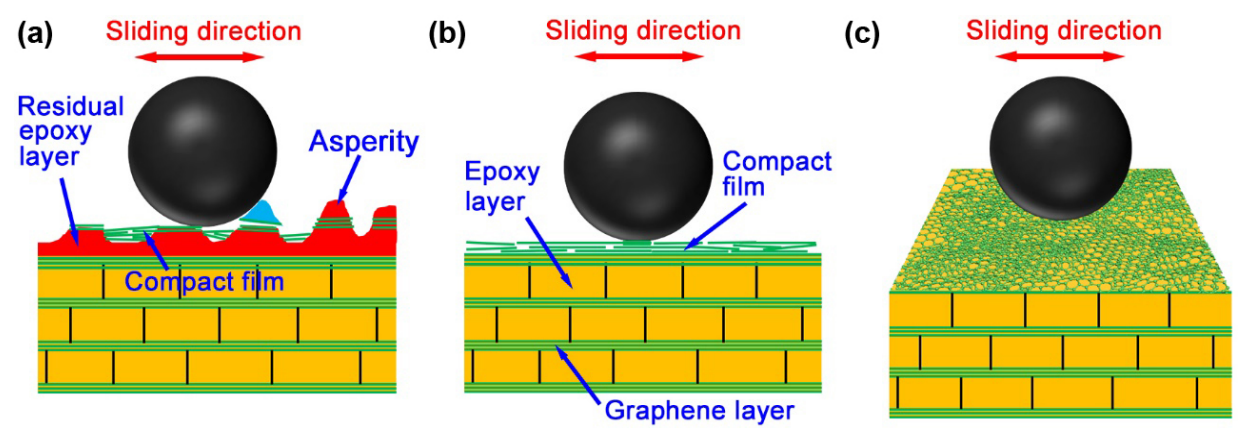

Fig. 10 Schematic representation about the formation of compact self-lubricating film. 
epoxy layer of AGEC. Frictional tests indicate the significantly enhanced role of tribological performance of epoxy resins resulted from the arrangement of graphene in epoxy matrix. Compared with neat epoxy and RGEC, AGEC has the best friction-reducing and anti-wear properties. Wear tracks observations reveal the formation of compact self-lubricating films made of numerous graphene sheets on the worn surface, of which the area increases with the increasing normal load. The presence of this film exerts its protective role in preventing the direct contact between two counterparts, reducing the contact stress, and thus leading to a high anti-wear property of AGEC. Therefore, the wear form of AGEC becomes mildly abrasive wear, compared with the severe fatigue wear of neat epoxy and the adhesion, abrasive, and fatigue wear of RGEC. Furthermore, this film is attributed with a low shear strength by the easily shear property of graphene sheets, and thereafter a low COF of AGEC is realized. The results of this study render AGEC a promising material in the field of tribology.

\section{Acknowledgements}

The authors acknowledge the financial supports from the National Key R\&D Program of China (2018YFA0703400), the Xinghai Science Funds for Distinguished Young Scholars at Dalian University of Technology, and the Collaborative Innovation Center of Major Machine Manufacturing in Liaoning.

Open Access This article is licensed under a Creative Commons Attribution 4.0 International License, which permits use, sharing, adaptation, distribution and reproduction in any medium or format, as long as you give appropriate credit to the original author(s) and the source, provide a link to the Creative Commons licence, and indicate if changes were made.

The images or other third party material in this article are included in the article's Creative Commons licence, unless indicated otherwise in a credit line to the material. If material is not included in the article's Creative Commons licence and your intended use is not permitted by statutory regulation or exceeds the permitted use, you will need to obtain permission directly from the copyright holder.
To view a copy of this licence, visit http://creativecommons.org/licenses/by/4.0/.

\section{References}

[1] Rahsepar M, Mohebbi F. Enhancement of the wear resistance of epoxy coating in presence of MBT-loaded mesoporous silica nanocontainers. Tribol Int 118: 148-156 (2018)

[2] Khafidh M, Schipper D J, Masen M A, Vleugels N, Dierkes W K, Noordermeer J W M. Validity of Amontons' law for run-in short-cut aramid fiber reinforced elastomers: The effect of epoxy coated fibers. Friction 8(3): 613-625 (2020)

[3] Zhang L, Xie G X, Wu S, Peng S G, Zhang X Q, Guo D, Wen S Z, Luo J B. Ultralow friction polymer composites incorporated with monodispersed oil microcapsules. Friction 9(1): 29-40 (2021)

[4] Huang Z P, Zhao W J, Zhao W C, Ci X J, Li W T. Tribological and anti-corrosion performance of epoxy resin composite coatings reinforced with differently sized cubic boron nitride (CBN) particles. Friction 9(1): 104-118 (2021)

[5] Yan L, Wang H Y, Wang C, Sun L Y, Liu D J, Zhu Y J. Friction and wear properties of aligned carbon nanotubes reinforced epoxy composites under water lubricated condition. Wear 308(1-2): 105-112 (2013)

[6] Khun N W, Zhang H, Lim L H, Yue C Y, Hu X, Yang J L. Tribological properties of short carbon fibers reinforced epoxy composites. Friction 2(3): 226-239 (2014)

[7] Sakka M M, Antar Z, Elleuch K, Feller J F. Tribological response of an epoxy matrix filled with graphite and/or carbon nanotubes. Friction 5(2): 171-182 (2017)

[8] Chen H Y, Jacobs O, Wu W, Rüdiger G, Schädel B. Effect of dispersion method on tribological properties of carbon nanotube reinforced epoxy resin composites. Polym Test 26(3): 351-360 (2007)

[9] Wang H Y, Yan L, Liu D J, Wang C, Zhu Y J, Zhu J H. Investigation of the tribological properties: Core-shell structured magnetic Ni@NiO nanoparticles reinforced epoxy nanocomposites. Tribol Int 83: 139-145 (2015)

[10] Wetzel B, Haupert F, Zhang M Q. Epoxy nanocomposites with high mechanical and tribological performance. Compos Sci Technol 63(14): 2055-2067 (2003)

[11] Chang L, Zhang Z, Ye L, Friedrich K. Tribological properties of epoxy nanocomposites: III. Characteristics of transfer films. Wear 62(5-6): 699-706 (2007)

[12] Chang L, Zhang Z, Breidt C, Friedrich K. Tribological properties of epoxy nanocomposites I. Enhancement of the wear resistance by nano- $\mathrm{TiO}_{2}$ particles. Wear 258(1-4): 141-148 (2005) 
[13] Shi G, Zhang M Q, Rong M Z, Wetzel B, Friedrich K. Friction and wear of low nanometer $\mathrm{Si}_{3} \mathrm{~N}_{4}$ filled epoxy composites. Wear 254(7-8): 784-796 (2003)

[14] Huang L, Zhu P L, Li G, Lu D Q, Sun R, Wong C P. Core-shell $\mathrm{SiO}_{2} @ \mathrm{RGO}$ hybrids for epoxy composites with low percolation threshold and enhanced thermo-mechanical properties. J Mater Chem A 2(43): 18246-18255 (2014)

[15] Tang L C, Wan Y J, Yan D, Pei Y B, Zhao L, Li Y B, Wu L B, Jiang J X, Lai G Q. The effect of graphene dispersion on the mechanical properties of graphene/epoxy composites. Carbon 60: 16-27 (2013)

[16] Naebe M, Wang J, Amini A, Khayyam H, Hameed N, Li L H, Chen Y, Fox B. Mechanical property and structure of covalent functionalised graphene/epoxy nanocomposites. Sci Rep 4: 4375 (2014)

[17] Lee C, Wei X D, Kysar J W, Hone J. Measurement of the elastic properties and intrinsic strength of monolayer graphene. Science 321(5887): 385-388 (2008)

[18] Balandin A A, Ghosh S, Bao W Z, Calizo I, Teweldebrhan D, Miao F, Lau C N. Superior thermal conductivity of singlelayer graphene. Nano Lett 8(3): 902-907 (2008)

[19] Tang J J, Yang J, Zhou L, Xie J, Chen G H, Zhou X Y. Layer-by-layer self-assembly of a sandwich-like graphene wrapped $\mathrm{SnO}_{x} @$ graphene composite as an anode material for lithium ion batteries. J Mater Chem A 2(18): 6292-6295 (2014)

[20] Yu S Y, Li N, Higgins D, Li D Y, Li Q, Xu H, Spendelow J S, Wu G. Self-assembled reduced graphene oxide/ polyacrylamide conductive composite films. ACS Appl Mater Inter 6(22): 19783-19790 (2014)

[21] Liu C, Yan H X, Lv Q, Li S, Niu S. Enhanced tribological properties of aligned reduced graphene oxide- $\mathrm{Fe}_{3} \mathrm{O}_{4} @$ polyphosphazene/bismaleimides composites. Carbon 102: 145-153 (2016)

[22] Liu C, Yan H X, Chen Z Y, Yuan L X, Liu T Y. Enhanced tribological properties of bismaleimides filled with aligned graphene nanosheets coated with $\mathrm{Fe}_{3} \mathrm{O}_{4}$ nanorods. J Mater Chem A 3(19): 10559-10565 (2015)

[23] Yao B W, Chen J, Huang L, Zhou Q Q, Shi G Q. Baseinduced liquid crystals of graphene oxide for preparing elastic graphene foams with long-range ordered microstructures. Adv Mater 8(28): 1623-1629 (2016)

[24] Lian G, Tuan C C, Li L Y, Jiao S L, Wang Q L, Moon K S, Cui D L, Wong C P. Vertically aligned and interconnected graphene networks for high thermal conductivity of epoxy composites with ultralow loading. Chem Mater 28(17): 6096-6104 (2016)

[25] Li Q, Guo Y F, Li W W, Qiu S Q, Zhu C, Wei X F, Chen M L, Liu C J, Liao S T, Gong Y P, et al. Ultrahigh thermal conductivity of assembled aligned multilayer graphene/epoxy composite. Chem Mater 15(26): 4459-4465 (2014)

[26] Dai W, Lv L, Lu J B, Hou H, Yan Q W, Alam F E, Li Y F, Zeng X L, Yu J H, Wei Q P, et al. A paper-like inorganic thermal interface material composed of hierarchically structured graphene/silicon carbide nanorods. ACS Nano 13(2): 1547-1554 (2019)

[27] Liang Q Z, Yao X X, Wang W, Liu Y, Wong C P. A ThreeDimensional Vertically Aligned Functionalized Multilayer Graphene Architecture: An Approach for Graphene-Based Thermal Interfacial Materials. ACS Nano 5(3): 2392-2401 (2011)

[28] Qiu L, Liu J Z, Chang S L Y, Wu Y, Li D. Biomimetic superelastic graphene-based cellular monoliths. Nat Commun 3: 1241 (2012)

[29] Hou H, Dai W, Yan Q W, Lv L, Alam F E, Yang M H, Yao Y G, Zeng X L, Xu J B, Yu J H, et al. Graphene sizedependent modulation of graphene frameworks contributing to the superior thermal conductivity of epoxy composites. J Mater Chem A 6(25): 12091-12097 (2018)

[30] Wang F, Wang H Y, Mao J. Aligned-graphene composites: A review. J Mater Sci 54(1): 36-61 (2019)

[31] Huang X, Qi X Y, Boey F, Zhang H. Graphene-based composites. Chem Soc Rev 41(2): 666-686 (2012)

[32] Shen X J, Pei X Q, Fu S Y, Friedrich K. Significantly modified tribological performance of epoxy nanocomposites at very low graphene oxide content. Polymer 54(3): 12341242 (2013)

[33] Bassani R, Levita G, Meozzi M, Palla G. Friction and wear of epoxy resin on inox steel: Remarks on the influence of velocity, load and induced thermal state. Wear 214(2): 125-132 (2001)

[34] Hutchings I, Shipway P. Tribology-friction and wear of engineering materials. Oxford (UK): Butterworth-Heinemann Press, 2017.

[35] Shimbo M, Ochi M, Ohoyama N. Frictional behaviour of cured epoxide resins. Wear 91(1): 89-101 (1983)

[36] Campo M, Jiménez-Suárez A, Ureña A. Effect of type, percentage and dispersion method of multi-walled carbon nanotubes on tribological properties of epoxy composites. Wear 324-325: 100-108 (2015)

[37] Malard L M, Pimenta M A, Dresselhaus G, Dresselhaus M S. Raman spectroscopy in graphene. Phys Rep 473(5-6): 51-87 (2009)

[38] Cancado L G, Jorio A, Ferreira E H, Stavale F, Achete C A, Capaz R B, Moutinho M V O, Lombardo, A, Kulmala T S, Ferrari A C. Quantifying defects in graphene via Raman spectroscopy at different excitation energies. Nano Lett 11(8): 3190-3196 (2011) 
[39] Scharf T W, Prasad S V. Solid lubricants: A review. J Mater Sci 48(2): 511-531 (2012)

[40] Bowden F P, Tabor D F. The friction and lubrication of solids. AM J Phys 19(7): 428-429 (1954)

[41] Berman D, Erdemir A, Sumant AV. Few layer graphene to reduce wear and friction on sliding steel surfaces. Carbon 54: 454-459 (2013)

[42] Berman D, Erdemir A, Sumant AV. Graphene: A new

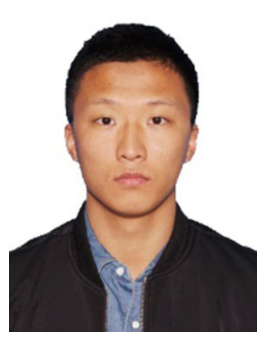

Yuefeng DU. He received his bachelor degree from Shenyang Jianzhu University, China, in 2015. He is currently a Ph.D. student in the Key Laboratory for Precision and

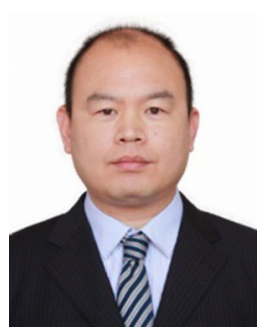

Zhenyu ZHANG. He received his B.E. degree in mechanical engineering in 2000 from Hebei Institute of Science and Technology, Tangshan, China. In 2003, he received M.E. degree in mechanical engineering from Hebei University of Technology,

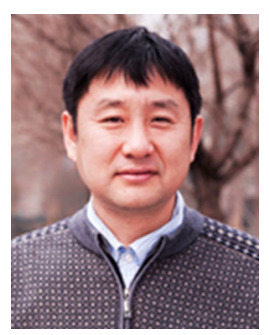

Nan JIANG. He received his Ph.D. degree from Osaka University, Japan, in 1997. His current position is a professor at Ningbo Institute emerging lubricant. Mater Today 17(1): 31-42 (2014)

[43] Stachowiak G W, Batchelor A W. Engineering Tribology. Oxford (UK): Butterworth-Heinemann Press, 2000.

[44] Huang T, Xin Y S S, Nutt S, Su C, Chen H M, Liu P, Lai Z L. Modified graphene/polyimide nanocomposites: Reinforcing and tribological effects. ACS Appl Mater Inter 5(11): 4878-4891 (2013)

Non-Traditional Machining Technology of Ministry of Education at Dalian University of Technology, Dalian, China. His research interests include macroscale superlubricity and graphene-epoxy self-lubricating composites.

Tianjin, China. After that, he obtained his Ph.D. degree in 2005 in solid mechanics from Tianjin University, Tianjin, China. His current position is a professor in mechanical engineering at Dalian University of Technology, Dalian, China. His research interests focus on precision and ultraprecision machining technologies, and high performance manufacturing.

of Materials Technology and Engineering, Chinese Academy of Sciences. His major research areas include chemical vapor deposition (CVD) diamond, graphene, and the related devices. 